\title{
Mulheres Livres: Mulher, Revolução e Anarquismo
}

Mujeres Libres: Mujer, Revolución y Anarquismo Free Women: Woman, Revolution and Anarchism

\author{
Glaucia Carvalho Sena' (iD ORCID 0000-0002-9947-5246 \\ Katiuscia Moreno Galhera' (iD ORCID 0000-0001-5790-0913 \\ 'Universidade Federal da Grande Dourados, Programa de Pós-Graduação em \\ Sociologia, Dourados, MS, Brasil. 79804-970 - mestradosociologia@ufgd.edu.br
}

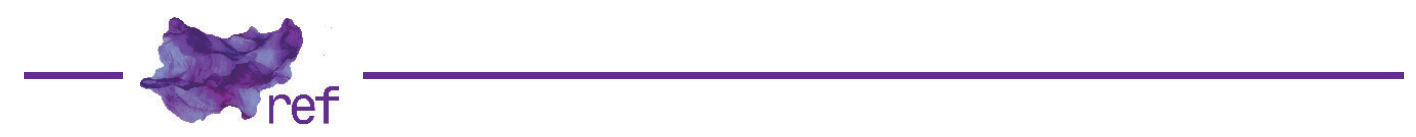

ACKELSBERG, Martha A.

Mulheres Livres: a luta pela emancipação feminina e a Guerra Civil Espanhola.

Trad. de Júlia Rabahie. São Paulo: Elefante, 2019.

Martha A. Ackelsberg é uma cientista política estadunidense, professora emérita de política e estudos de mulheres e gênero do Smith College em Northampton, Massachusetts, Estados Unidos. Lecionou cursos de política urbana, participação política, teoria feminista, teoria democrática e anarquismo. Ackelsberg estudava questões de identidade, diferença e comunidade. A escrita do livro faz parte da vontade da autora de contar a história de um grupo de mulheres e do movimento que faziam parte (Martha ACKELSBERG, 2019, p. 120).

Mulheres Livres foi lançado no Brasil, em 2019, pela editora Elefante a partir da tradução publicada originalmente em inglês, nos Estados Unidos. O livro é particularmente relevante na literatura em língua portuguesa, devido à relativa escassez de publicações com os temas mulher, revolução e anarquismo nessa língua. Outro fator que torna a obra especialmente relevante é a abordagem de tais temas com outras revoluções similares em curso, como 0 Zapatismo e a Revolução Curda. Ainda, o volume é um registro inédito importante das memórias das militantes anarquistas espanholas e apresenta outros documentos (†odos dados primários). A obra, ao longo das suas 410 páginas, tem o objetivo de apresentar a fundação da associação Mulheres Livres na Espanha, o desenvolvimento e a sua atuação. A autora relata que tinha uma fascinação pela organização, principalmente pelo aparente distanciamento das integrantes com o movimento feminista (ACKELSBERG, 2019, p. 35).

Dividido em seis capítulos, o livro aborda em especial a experiência anarquista e de libertação das mulheres no contexto da Revolução Espanhola durante a Guerra Civil Espanhola (1936-1939): a primeira de cunho abertamente antifascistal. No primeiro capítulo, intitulado "A

1 Diversas experiências caracterizam a revolução, como a coletivização de terras nos territórios controlados por anarquistas, diferentemente da dos territórios sobre controle soviético da Revolução Russa (cabe lembrar que nessa época a Espanha era um país predominantemente rural). Antifascista é provavelmente um dos termos mais 
revolução anarquista e a libertação das mulheres", Martha aborda em especial o movimento anarquista e o grupo Mulheres Livres no contexto da Confederación Nacional del Trabajo e da Federación Anarquista lbérica (CNT-FAl), organização na qual essas mulheres eram filiadas. O segundo capítulo - "Mobilização da comunidade e organização sindical: as mulheres e o movimento anarquista espanhol" - analisa historicamente o movimento anarquista na Espanha (em especial a área da educação) e a questão de gênero. O terceiro capítulo, "Guerra civil e revolução social", descreve a situação política do país, os conflitos militares e a experiência de ativistas anarquistas e socialistas. O capítulo seguinte - "A fundação da Mulheres Livres" explora as experiências das fundadoras na Mulheres Livres dentro do anarcossindicalismo. $O$ quinto capítulo - "Educação e empoderamento" - aborda o funcionamento dos programas de capacitação e conscientização das mulheres. Por fim, o último capítulo - "Diferentes e iguais? Dilemas da organização revolucionária" - exprime os motivos da Mulheres Livres ser diferente das outras organizações, ainda que sua fundação fosse alinhada à prática anarquista.

Mulheres Livres foi primeiro uma revista e depois uma organização fundada por mulheres revolucionárias, dentre elas a escritora Lucia Sánchez Saornil, pela advogada Mercedes Comaposada e pela médica Amparo Pach y Gascón2. A Confederación Nacional del Trabajo possuía bases ideológicas anarquistas que compartilhavam com os demais ideais libertários, por exemplo, a tradição comunalista e a emancipação enquanto processo coletivo (com o maior número de pessoas possível, incluindo, mas não apenas, trabalhadores/as urbanos/as). Porém, essas mulheres consideravam que havia problemas na abordagem das questões das mulheres na CNT-FAl e na sociedade em geral.

Como um movimento dentro do movimento - um movimento de mulheres dentro do movimento anarcossindicalista - a Mulheres Livres começou como um grupo independente e autônomo no início da Guerra Civil, com programas e ações diferentes das demais organizações que compunham o movimento anarcossindicalista, centrando a sua atenção e esforços nas relações entre a subordinação econômica, cultural e sexual das mulheres. Desta forma, a Mulheres Livres nasceu de uma situação de conflito e cooperação com camaradas: ao mesmo tempo em que achavam a sua organização anarcossindicalista inadequada para lidar plenamente com as questões de gênero, não havia outra organização melhor para combater a ditadura de Francisco Franco (1892-1975) e o fascismo daí derivado.

O grupo começou suas atividades na cidade de Barcelona no fim de 1934; embora o grupo barcelonês fosse o mais proeminente, havia outro grupo também em Madrid. Apesar do legado, as atividades da Mulheres Livres acabaram sendo interrompidas por conta da ascensão das forças do ditador Franco e o fim da Guerra Civil, com a duração de três anos (ACKELBERG, 2019 , p. 31). Apesar do breve período, o grupo mobilizou mais de 20 mil pessoas em diversas atividades e em uma rede ampla de cooperação (ACKELSBERG, 2019, p. 13).

Dentre as atividades, a associação buscou principalmente a garantia da emancipação feminina (chamada de "empoderamento" pela autora) a partir do que denominavam como tripla condição de escravidão: escravidão da ignorância, como mulher e como trabalhadora (ACKELSBERG, 2019, p. 262). O compromisso da Mulheres Livres era duplo: com a educação e a militância. Por este motivo, a educação era um dos pilares da Mulheres Livres para emancipação das mulheres, pois pela educação as mulheres poderiam se preparar para o compromisso revolucionário e poderiam se fortalecer e adquirir autoconfiança (AKELSBERG, 2019, p. 262). A educação tinha o poder para libertar o potencial das mulheres, o que permitiria que se transformassem em integrantes ativas no movimento libertário e na nova sociedade (ACKELSBERG, 2019, p. 268).

A Mulheres Livres tinha, ainda, programas voltados para a maternidade, para o cuidado dos/as filhos/as e sobre sexualidade. No tocante à maternidade, a organização defendia que as mulheres tinham identidade e função social, independente do potencial e status de mãe. A responsabilidade com a educação e formação dos/as filhos/as pesava mais sobre as mulheres, então a Mulheres Livres julgava a importância da educação para que as mães pudessem instruir e orientar seus filhos. O amor livre, frequentemente atribuído à Mulheres Livres, não era assim tão bem aceito: em realidade, as companheiras passavam a ser vistas como libertinas e até mesmo chamadas jocosamente de "mujeres liebres" (mulheres lebres) se tinham mais de um parceiro sexual (ACKELBERG, 2019, p. 334). Eram, ainda, acusadas de irem ao front de guerra para se prostituírem, comprometendo a saúde e moral dos homens (ACKELBERG, 2019, p. 182).

Na década de 1930, a Espanha era um país já com grandes desigualdades de gênero, inclusive dentro de movimentos de luta. Assim, questões de desigualdades salariais entre homens

apropriados para definir a Revolução Espanhola, já que a Guerra Civil Espanhola tinha como característica o confronto entre forças contraditórias: republicanos, anarquistas, comunistas (trotskistas no Partido Operário de Unificação Marxista/POUM e stalinistas do Partido Comunista de Espanha/PCE) contra o golpe de Franco e o fascismo (a conjunção de forças do fascismo europeu).

2 Também fizeram parte da Mulheres Livres as seguintes militantes: Suceso Portales, Lola lturbe, Azucena e Enriqueta Fernández Barba, Sara Berenger Guillén, Pepita Carpeña e Soledad Estorach. 
e mulheres e postos de maior status social majoritariamente masculinos andavam em paralelo com lideranças sindicais e representações nos comitês de fábrica igualmente composta por homens em sua maior parte. No movimento anarcossindicalista não era diferente: a maior parte dos coletivos estabelecidos durante a Revolução, por exemplo, pegavam salários ao "chefe da família", conforme o número, sexo e idade das pessoas (ACKELSBERG, 2019, p. 194-195, 203). Por fim, embora a associação tenha insistido para ser tratada com respeito e seriedade e, inclusive, ter pedido apoio financeiro à FAl, em 1937, a Mulheres Livres recebeu 1/16 do pedido original. Emma Goldman chegou a entrar em defesa da Mulheres no quesito apoio - financeiro e moral - junto à CNT, em 19363, mas a tese proudhoniana do status secundário das mulheres parecia vigorar efetivamente (ACKELSBERG, 2019, p. 222-224).

Um ponto importante sobre a Mulheres Livres é que a associação não se reivindicava como feminista, embora lutasse ativamente pela emancipação das mulheres: ainda que o foco na questão do gênero fosse explícito, a associação entendia que gênero estava dissociado da luta coletiva e do movimento libertário. Em paralelo a Emma Goldman, a natureza interna da luta (também entendida como o respeito das mulheres por si mesmas) era critério essencial para o respeito dos homens e, portanto, para a luta coletiva. O rechaço à definição de "feminista" tinha ainda outras razões de ser: o papel do humanismo - comum, por exemplo, nas experiências pedagógicas de Francisco Ferrer, frequentemente considerado anarquista -, enquanto referência filosófica e conceitual predominava, e o movimento sufragista, como referência feminista, tinha certa dificuldade em endereçar questões de classe tão caras para a Mulheres Livres. A revolucionária Federica Montseny foi provavelmente a mais crítica nesse quesito: "Feminismo? Nunca! Humanismo, sempre [...] Feminismo, palavra aplicável somente a mulheres ricas" (ACKELSBERG, 2019, p. 224-226).

O livro traz algumas questões que são passíveis de complexificação. Em primeiro lugar, o uso do termo empoderamento é um tanto descontextualizado: sua apropriação frequentemente liberal, por exemplo, pela Organização das Nações Unidas (ONU) e por propagandas capitalistas pode confundir o significado dos termos do debate. Em segundo lugar, a análise da autora se foca em duas variáveis - classe e gênero - ignorando a solidariedade de militantes da Revolução Espanhola com as lutas anticoloniais de viés de raça mais exacerbado e de outros projetos de emancipação dos povos da periferia do sistema capitalista, para citar apenas um exemplo.

A despeito desses vazios, Mulheres Livres é um importante registro de memórias e um relevante compilado bibliográfico. Martha Ackelsberg realizou um trabalho de revisão bibliográfica e entrevistas in loco de fôlego, pontos de partida que sozinhos fazem o livro valer a pena. $O$ volume pode interessar militantes de movimentos sociais (especialmente feministas e revolucionários), pessoas interessadas nas lutas das mulheres e acadêmicas em geral.

\section{Referência}

ACKELSBERG, Martha A. Mulheres Livres: a luta pela emancipação feminina e a Guerra Civil Espanhola. Trad. de Júlia Rabahie. São Paulo: Elefante, 2019.

Glaucia Carvalho Sena (glaucia.sena054@ufgd.edu.br) é graduada em Relações Internacionais e Mestranda no Programa de Pós-Graduação em Sociologia na Universidade Federal da Grande Dourados (PPGS/UFGD), com bolsa CAPES (Coordenação de Aperfeiçoamento de Pessoal de Nível Superior).

Katiuscia Moreno Galhera (katiusciagalhera@ufgd.edu.br) é Doutora em Ciência Política (UNICAMP) com visiting scholar period em direitos globais de trabalhadores(as) na Penn State University (PSU) e estágio pós-doutoral em Sociologia (UEL). Atualmente, é professora visitante do Programa de Pós-Graduação em Sociologia da Universidade Federal da Grande Dourados (PPGS-UFGD).

\footnotetext{
${ }^{3}$ Também conhecido como Congresso de Zaragoza, de maio de 1936, em especial o documento Dictamen sobre "Concepto confederaldel comunismo libertário".
} 
COMO CITAR ESTE ARTICO DE ACORDO COM AS NORMAS DA REVISTA

GALHERA, Katiuscia Moreno; SENA, Glaucia Carvalho. "Mulheres Livres: Mulher, Revolução e Anarquismo". Revista Estudos Feministas, Florianópolis, v. 29, n. 3, e79498, 2021.

\section{CONTRIBUIÇĀO DE AUTORIA}

As autoras contribuíram igualmente.

\section{FINANCIAMENTO}

O presente trabalho foi realizado com apoio da Coordenação de Aperfeiçoamento de Pessoal de Nível Superior - Brasil (CAPES) - Código de Financiamento 001.

\section{CONSENTIMENTO DE USO DE IMAGEM}

Não se aplica.

\section{APROVAÇĀO DE COMITÊ DE ÉTICA EM PESQUISA}

Não se aplica.

\section{CONFLITO DE INTERESSES}

Não se aplica.

\section{LICENÇA DE USO}

Este artigo está licenciado sob a Licença Creative Commons CC-BY 4.0 International. Com essa licença você pode compartilhar, adaptar, criar para qualquer fim, desde que atribua a autoria da obra.

\section{HISTÓRICO}

Recebida em 12/02/2021

Aceita em 24/05/2021 